\title{
Multicentric carpo-tarsal osteolysis with or without nephropathy
}

INSERM

\section{Source}

INSERM. (1999). Orphanet: an online rare disease and orphan drug data base.

Multicentric carpo-tarsal osteolysis with or without nephropathy. ORPHA:2774

Idiopathic multicentric osteolysis is a very rare syndrome characterized by progressive loss of bone, usually the capsal and tarsal bones, resulting in deformity and disability, as well as chronic renal failure in many cases. The bone and renal disorders are sometimes associated with intellectual deficit and facial abnormalities. 